\title{
Spatiotemporal Transmission Patterns and Determinants of Dengue Fever: A Case Study of Guangzhou, China
}

\author{
Yebin Chen ${ }^{1,2}$, Zhigang Zhao ${ }^{2}$, Zhichao $\mathrm{Li}^{3}$, Weihong $\mathrm{Li}^{4}$, Zhipeng $\mathrm{Li}^{5}$, Renzhong Guo ${ }^{1,2, *}$ and \\ Zhilu Yuan ${ }^{2}$ (D) \\ 1 School of Resource and Environmental Sciences, Wuhan University, Wuhan 430072, China \\ 2 Research Institute of Smart City, School of Architecture and Urban Planning, Shenzhen University, \\ Shenzhen 518060, China \\ 3 Ministry of Education Key Laboratory for Earth System Modeling, Department of Earth System Science, \\ Tsinghua University, Beijing 100084, China \\ 4 School of Geography, South China Normal University, Guangzhou 510631, China \\ 5 Institute of Digital Agriculture Research, Fujian Academy of Agricultural Sciences, Fuzhou 350003, China \\ * Correspondence: guorz@szu.edu.cn; Tel.: +86-155-2112-0687
}

Received: 8 June 2019; Accepted: 10 July 2019; Published: 12 July 2019

\begin{abstract}
Dengue fever is one of the most common vector-borne diseases in the world and is mainly affected by the interaction of meteorological, human and land-use factors. This study aims to identify the impact of meteorological, human and land-use factors on dengue fever cases, involving the interplay between multiple factors. The analyses identified the statistically significant determinants affecting the transmission of dengue fever, employing cross-correlation analysis and the geo-detector model. This study was conducted in Guangzhou, China, using the data of confirmed cases of dengue fever, daily meteorological records, population density distribution and land-use distribution. The findings highlighted that the dengue fever hotspots were mainly distributed in the old city center of Guangzhou and were significantly shaped by meteorological, land-use and human factors. Meteorological factors including minimum temperature, maximum temperature, atmospheric pressure and relative humidity were correlated with the transmission of dengue fever. Minimum temperature, maximum temperature and relative humidity presented a statistically significant positive correlation with dengue fever cases, while atmospheric pressure presented statistically significant negative correlation. Minimum temperature, maximum temperature, atmospheric pressure and humidity have lag effects on the transmission of dengue fever. The population, community age, subway network density, road network density and ponds presented a statistically significant positive correlation with the number of dengue fever cases, and the interaction among land-use and human factors could enhance dengue fever transmission. The ponds were the most important interaction factors, which might strengthen the influence of other factors on dengue fever transmission. Our findings have implications for pre-emptive dengue fever control.
\end{abstract}

Keywords: dengue fever; spatial interactions; geo-detector; determinants

\section{Introduction}

Dengue fever (DF) is an acute mosquito-borne disease caused by dengue virus and transmitted by Aedes mosquitoes [1]. This disease has a high incidence rate, rapid transmission speed and high mortality rate in critically ill patients [2]. The clinical manifestations of DF patients are fever, severe headache, muscle and joint pain and some patients have lymphadenopathy, rash and even bleeding tendency $[1,3,4]$. The global spread of DF has caused serious economic losses to people living in 
tropical and subtropical countries [1,5]. Evidence has shown that more than 100 countries and regions comprising 2.5 billion people are facing the threat of $\mathrm{DF}$, which poses great challenges to global public health [6-9].

In mainland China, DF cases have been reported every year since 1997, especially in Guangdong Province. The DF incidence rate in 2014 was the highest in the Guangdong Province in the past 30 years, and Guangzhou city (the capital and most populous city of Guangdong Province) is the most seriously affected area. In 2014, 37,386 confirmed DF cases were found in Guangzhou city, accounting for $82.67 \%$ of the total number of DF cases in Guangdong Province. Aedes albopictus and Aedes aegypti are the main DF vectors in Guangzhou [10]. Referring to mosquito breeding and DF transmission, meteorological conditions [11,12] as well as human (demographic structure, population size) [13-15] and land-use factors (traffic, standing water) $[16,17]$ have been identified as important factors affecting the transmission of DF disease. For example, mosquito breeding activities are affected by temperature: Aedes albopictus are most active in breeding activities when the temperature is between $26^{\circ} \mathrm{C}$ and $30{ }^{\circ} \mathrm{C}$, but the feeding activity of mosquitoes decreases and mortality increases when the temperature is lower than $15^{\circ} \mathrm{C}$ or higher than $35^{\circ} \mathrm{C}$ [12]. Rainfall and humidity are positively associated with the reproduction of Aedes at the initial life stage of Aedes mosquitoes [18]. Poor sanitation, wet areas and densely populated areas are ideal places for Aedes mosquito breeding [1,19].

Patterns and determinants relating to DF transmission have been investigated in many studies. However, existing studies neglect the interactions between impacting factors when examining the statistical relationships between factors (e.g., meteorology, human factors, etc.) and DF transmission [6,13]. Moreover, when constructing models to identify the spatial patterns of transmission and its determinants, most studies only investigate the effect of each factor on DF at the local level (e.g., using a geographically weighted regression model), without examining the interactions between multiple factors from a spatial perspective as well as incorporating the interplay of multiple factors in spatial models [20]. The spatiotemporal transmission of DF is the product of a multifactorial combination. The spatial interaction among various factors may strengthen the process of DF transmission [1]. Therefore, it is necessary to examine the spatial interactions between factors before examining the effect of factors on DF cases.

Within this context, this study aims to identify the impact of meteorological, human and land-use factors on DF cases, incorporating the spatial interactions between multiple factors. We employed the cross-correlation model to examine the impact of meteorological factors on DF transmission and the geo-detector model to examine the spatial interactions between human and land-use factors, and then investigated the impact of these factors and their interactions on DF transmission. Moreover, we conducted DF spatiotemporal transmission characteristics analysis in Guangzhou to clarify the potential impact of various factors on DF in detail, which lays the foundation for further identifying the impacting factors. The findings of this study could provide an important reference for prevention and control in cities with a high risk of DF.

\section{Materials and Methods}

\subsection{Study Area}

Located in the south-central part of Guangdong Province in China, Guangzhou $\left(112^{\circ} 57^{\prime}-114^{\circ} 3^{\prime}\right.$ E, $\left.22^{\circ} 26^{\prime}-23^{\circ} 56^{\prime} \mathrm{N}\right)$ is composed of Yuexiu, Liwan, Haizhu, Tianhe, Baiyun, Luogang, Huangpu, Panyu, Huadu, Nansha, Zengcheng and Conghua districts and had a resident population of 14.49 million and an overall area of $7434.4 \mathrm{~km}^{2}$ in 2014 (Figure 1). The average annual temperature in Guangzhou in 2014 was between 18.7 and $26.7^{\circ} \mathrm{C}$; the hottest month was July, and the coldest month was January. The rainy season was concentrated in April to June, and the annual average relative humidity was $81 \%$. However, due to the obsolete urban drainage system in the old city center (Yuexiu district), the annual flood season from April to June was prone to produce urban waterlogging, which provided conditions for mosquito breeding. 
Guangzhou was selected as the study area because it has always been the hardest hit area of DF in Guangdong Province and China [10]. Since 2001, the DF epidemic in Guangzhou has gradually intensified. Large-scale DF outbreaks happened in 2002, 2006 and 2014, and the outbreak in 2014 was the most serious one. The cumulative reported cases in 2014 reached 37,386 cases, which was the most serious DF epidemic in Guangzhou in the past 30 years. Guangzhou is the center of transportation, finance, industry and trade in southern China and has frequent economic and cultural communication with the nations of Southeast Asia and Africa, which also increased the importation risk of DF.

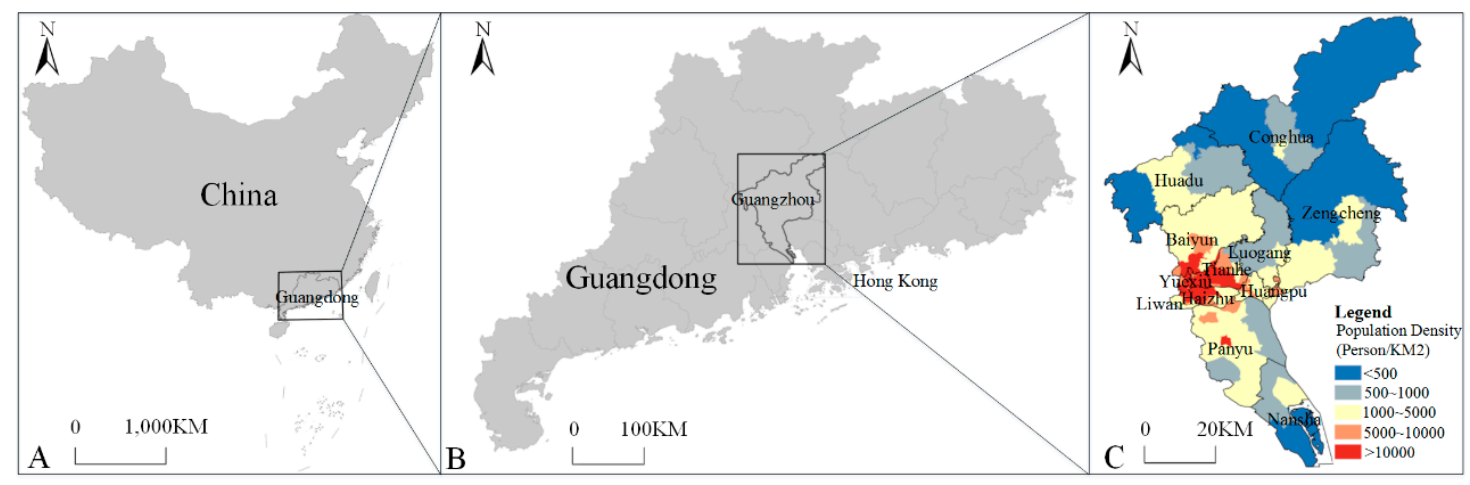

Figure 1. Extent of the study area. (A) The location of Guangdong Province in China; (B) the location of the study area in Guangdong Province; $(\mathbf{C})$ the extent of the study area and population density distribution.

\subsection{Data Collection}

\subsubsection{Dengue Fever Data}

DF cases were confirmed by epidemiological investigation and laboratory diagnosis. Patients suspected of having DF included those who lived or traveled to DF endemic areas (over 14 days) and subsequently exhibited clinical symptoms such as fever, with two or more of these manifestations: nausea, vomiting and skin erythema. Medical professionals were responsible for the clinical classification of the disease, along with laboratory confirmation through serology, NS1 (non-structural protein 1) test or polymerase chain reaction (PCR) tests [21]. Acute phase sera were tested by enzyme linked immunoassay (ELISA) for the detection of dengue NS1 antigen and dengue IgM antibodies. Convalescent phase sera were also tested by dengue IgM ELISA to identify seroconversions. Acute phase sera from suspected patients who were positive by NS1 ELISA or IgM ELISA in either the acute or the convalescent phase sera were also tested by reverse transcriptase polymerase chain reaction (RT-PCR) to identify the infecting serotype [22]. We defined a confirmed case of DF as a DF-suspected patient with a positive NS1 ELISA, acute or convalescent phase IgM ELISA or RT-PCR. The Chinese Ministry of health lists DF as a compulsory notification disease. According to the guidelines for DF case surveillance, county-level disease prevention and control agencies should record all DF cases and send them to the Information System for Notifiable Disease (ISND).

In this paper, the data of confirmed cases of DF were provided by Guangdong Provincial Center for Disease Control and Prevention, including all the DF confirmed cases of Guangzhou reported in ISND, totaling 37,386 cases from 1 January 2014 to 31 December 2014. Data structures of DF cases included the onset date, residence address, longitude and latitude attributes. Data were processed using ArcMap 10.2 (Environment System Research Institute, Inc., New York, NY, USA) to obtain the DF spatial distribution (Figure 2). 


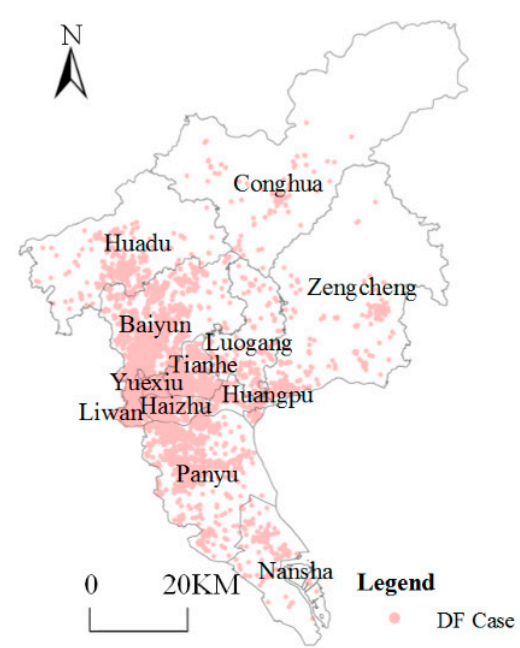

Figure 2. Spatial distribution of dengue fever (DF) cases.

\subsubsection{Factor Data}

Table 1 shows the data used in this study, including the meteorological data, human data and land-use data.

Table 1. The factor data used in the study.

\begin{tabular}{lllc}
\hline \multicolumn{1}{c}{ Factor Type } & \multicolumn{1}{c}{ Variables } & \multicolumn{1}{c}{ Description } & Unit \\
\hline \multirow{4}{*}{ Meteorological Data } & Minimum Temperature & Daily minimum temperature & ${ }^{\circ} \mathrm{C}$ \\
& Maximum Temperature & Daily maximum temperature & ${ }^{\circ} \mathrm{C}$ \\
& Atmospheric Pressure & Daily atmospheric pressure & $\begin{array}{c}\mathrm{hPa} \\
\%\end{array}$ \\
& Relative Humidity & Daily relative humidity & - \\
Human Data & Population & Number of people on the building & - \\
& Community age & Time span from the completion of & Years \\
& & the residential community to 2014 & \\
\hline \multirow{2}{*}{ Land-use Data } & Road & Road network density & $\mathrm{km} / \mathrm{km}^{2}$ \\
& Subway & Subway lines network density & $\mathrm{km} / \mathrm{km}^{2}$ \\
& Ponds & Ponds area & $\mathrm{m}^{2}$ \\
\hline
\end{tabular}

The meteorological data were provided by the Wushan meteorological monitoring station in Guangzhou, including daily minimum temperature (Tmin), maximum temperature (Tmax), atmospheric pressure (AP) and relative humidity (Hum) data, with a total of 365 records. Daily meteorological data were used to calculate the weekly average value (Figure 3), and the data were presented in Microsoft Excel 2013. 


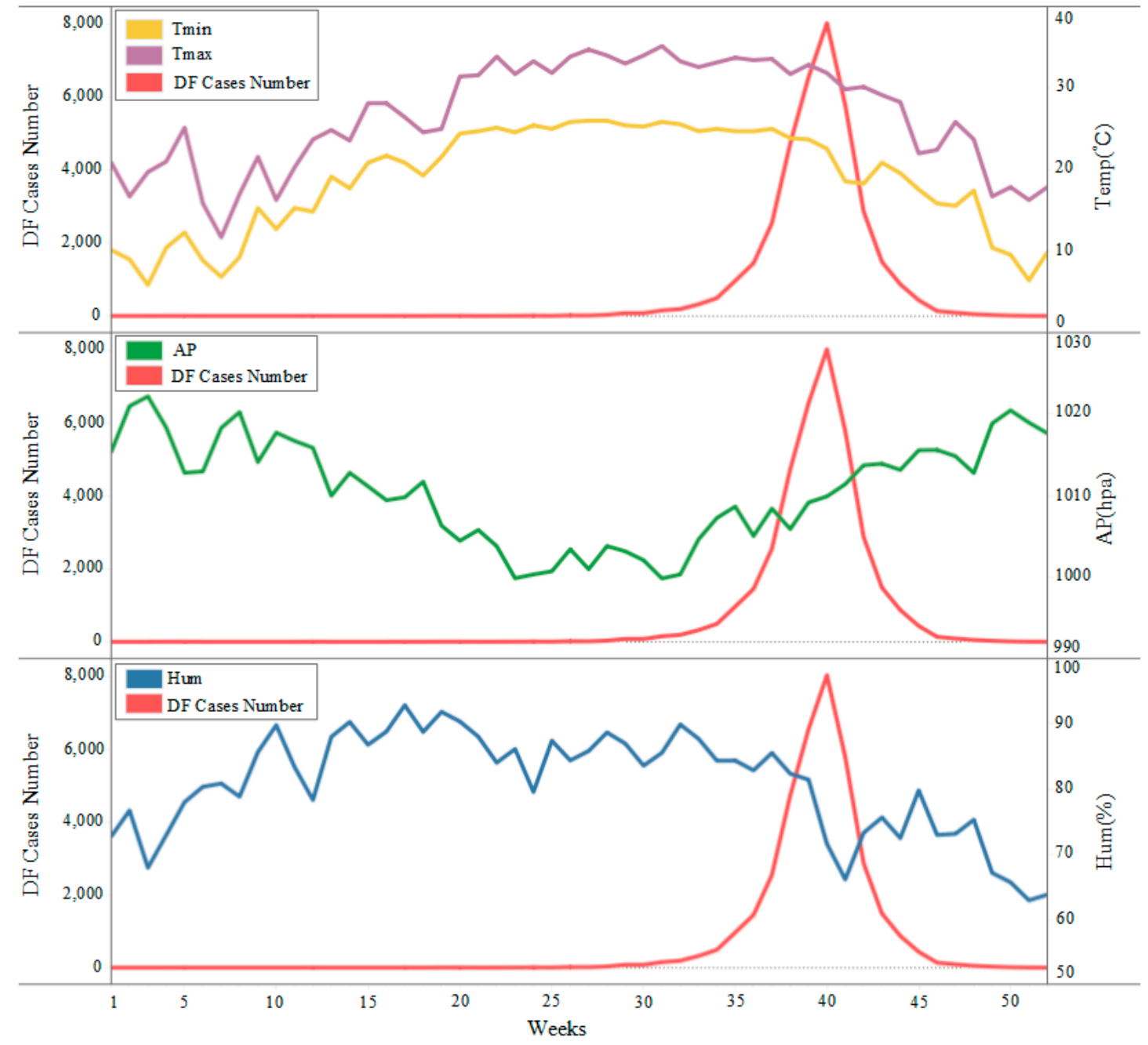

Figure 3. Sequence of weekly DF cases and meteorological factors in Guangzhou, 2014.

The land-use data were extracted from a $2.5 \mathrm{~m}$ SPOT (Système Probatoire d'Observation de la Terre) satellite remote sensing image and Baidu map (https://map.baidu.com) in 2014 by combining an automatic extraction algorithm (i.e., the Modified Normalized Difference Water Index, MNDWI) with manual vectorization, including roads, subways, ponds and residential areas, and the results of extracted land-use data were superimposed with images for verification. Roads include highways, national highways, provincial highways, urban expressways and county roads. Ponds refer to water areas with different sizes (e.g., $<1000 \mathrm{~m}^{2}$ ) and a relatively regular shape. Residential areas refer to residential buildings.

The human data include population and community age data. The data of population size were collected from the Guangzhou statistics bureau, and the points of interest (POI) of the residential community were collected from the Baidu map (https://map.baidu.com), which is the most popular map engine in China. The residential community POI included the location and the building time attributes, and the community age refers to the length of time from the time the community was built to 2014. The older the community, the worse the infrastructure and sanitation, which was more likely to lead to DF transmission [1]. The population data were distributed to each building according to the ratio of the total area of buildings (accumulated by the plane area of each floor) and the building area, while avoiding the homogenization problem that was caused by traditional sampling methods and improving the accuracy of the population data. 


\subsection{Methodology}

The paper aimed to analyze the impacts of meteorological factors, human factors and land-use factors on DF transmission. The analysis was divided into two parts. Firstly, we adopted cross-correlation analysis to analyze the impacts of meteorological factors (including minimum temperature, maximum temperature, relative humidity and atmospheric pressure) on the DF transmission given that meteorological factors have temporal characteristics. Secondly, the geographical detector model (geo-detector) was employed to analyze the interaction between human factors and land-use factors on DF transmission. In addition, we conducted DF spatiotemporal transmission characteristics analysis in Guangzhou to clarify the DF hotspots and help identify the potential impact of various factors in detail.

\subsubsection{Cross-Correlation Analysis}

DF transmission mainly depends on mosquito breeding activities. Meteorological factors, such as temperature, relative humidity and atmospheric pressure, could affect the breeding activities of mosquito vectors $[1,12,18,23]$. Increased temperature could stimulate the breeding activity of mosquito vectors; increased rainfall and relative humidity could increase mosquito breeding sites, and decreased atmospheric pressure could increase the contact probability of Aedes mosquitoes and people. Therefore, we selected minimum temperature, maximum temperature, relative humidity and atmospheric pressure to study the impact of meteorological factors on DF transmission.

Cross-correlation analysis can be used to analyze the correlation between meteorological factors and DF with different time lags [24]. In order to study the impact of temperature, relative humidity and atmospheric pressure on DF transmission, the cross-correlation analysis method was adopted to study the impact of the minimum temperature, maximum temperature, relative humidity and atmospheric pressure on DF transmission with different weekly lags (with the maximum delay time set as 12 weeks [25]). The related operations were completed in SPSS 22 V22.0 (IBM, Armonk, NY, USA).

\subsubsection{Geo-Detector Analysis}

Human and land-use factors were also key factors affecting mosquito breeding, including population size, traffic network density, the distribution of aging infrastructure and standing water. The increase of population size and traffic network density could increase the risk of healthy people being exposed to dengue carriers and Aedes mosquitoes [16], and the distribution of old city infrastructure and standing water affected the spatial distribution of the Aedes mosquitoes $[1,23,24]$. Therefore, this study selected population size, road network density, subway network density, community age and pond distribution to study the impact of human factors and land-use factors on DF.

The grid method and geo-detector analysis were conducted to explore the relationship between $\mathrm{DF}$ and various potential factors from a microscopic perspective using the data of DF and the potential driving factors. The study area was divided into 154 rows $\times 112$ columns by using a $1 \mathrm{~km} \times 1 \mathrm{~km}$ grid (according to the flight distance of mosquitoes; it is generally believed that the range of the mosquito's activity is mainly within $100 \mathrm{~m}$ of its birthplace, and the maximum is no more than $1 \mathrm{~km}$ [23]), making a total of 7745 grids. The DF cases and the 5 potential driving factors-population, community age, subway, roads and ponds-were spatialized into each grid using ArcGIS 10.2 (Environment System Research Institute, Inc., New York, NY, USA).

A factor-detector is a submodule of the geo-detector [26-28] which was used to identify the effects of each factor on the transmission process of DF. The factor-detector model can be written as follows:

$$
q_{D, H}=1-\frac{1}{n \sigma_{H}^{2}} \sum_{i=1}^{m} n_{D, i} \sigma_{H_{D, i}}^{2}
$$


where $q_{D, H}$ is the influence value of factor $\mathrm{D}$ on $\mathrm{DF} \mathrm{H} ; \sigma_{H}^{2}$ is the variance of DF throughout the area; $n$ is the number of samples in the study area; $m$ is the number of secondary areas; $\sigma_{H_{D, i}}^{2}$ is the variance of the DF number in the secondary level, when $\sigma_{H_{D, i}}^{2}$ is not equal to 0 , and the model is constructed. $q_{D, H} \in[0,1]$, when $q_{D, H}=0$, it indicates that the number of DF is not affected by factors. The larger the $q_{D, H}$, the greater the ability to explain the transmission process of DF. When $q_{D, H}=1$, the interpretation effect is optimal. The interaction detector is also a submodule of the geo-detector which can explore the interaction effect among factors. The model can be written as follows:

$$
\begin{gathered}
q_{D, H}\left(D_{i} \cap D_{j}\right)>q_{D, H}\left(D_{i}\right)+q_{D, H}\left(D_{j}\right): \text { Nonlinear synergy } \\
q_{D, H}\left(D_{i} \cap D_{j}\right)<q_{D, H}\left(D_{i}\right)+q_{D, H}\left(D_{j}\right): \text { Nonlinear antagonism } \\
q_{D, H}\left(D_{i} \cap D_{j}\right)=q_{D, H}\left(D_{i}\right)+q_{D, H}\left(D_{j}\right): \text { Independence }
\end{gathered}
$$

\section{Analyses and Results}

\subsection{Spatiotemporal Transmission Characteristics Analysis}

Figure 3 describes the time distribution characteristic of DF. From January to May (1-21 weeks), DF cases appeared slowly, and only 8 cases occurred during this period. From June to October (22-43 weeks), the DF cases number increased rapidly, with a total of 36,170 cases. DF showed an outbreak trend in this stage. From November to December (44-52 weeks), the number of DF cases decreased.

Figure 4 shows the monthly spatiotemporal hotspot distribution of DF. It highlights that the DF initially tended to spread into the old city center (Yuexiu district), thus exhibiting obvious aggregation characteristics, and then spread rapidly to surrounding areas-Liwan, Haizhu, Baiyun and Tianhe districts-showing the characteristics of "high center and low periphery", and finally covering the entire city.

Figure 5 describes the monthly gravity center of DF, which indicates that monthly gravity centers of DF were mainly concentrated in the southeastern part of Yuexiu District.

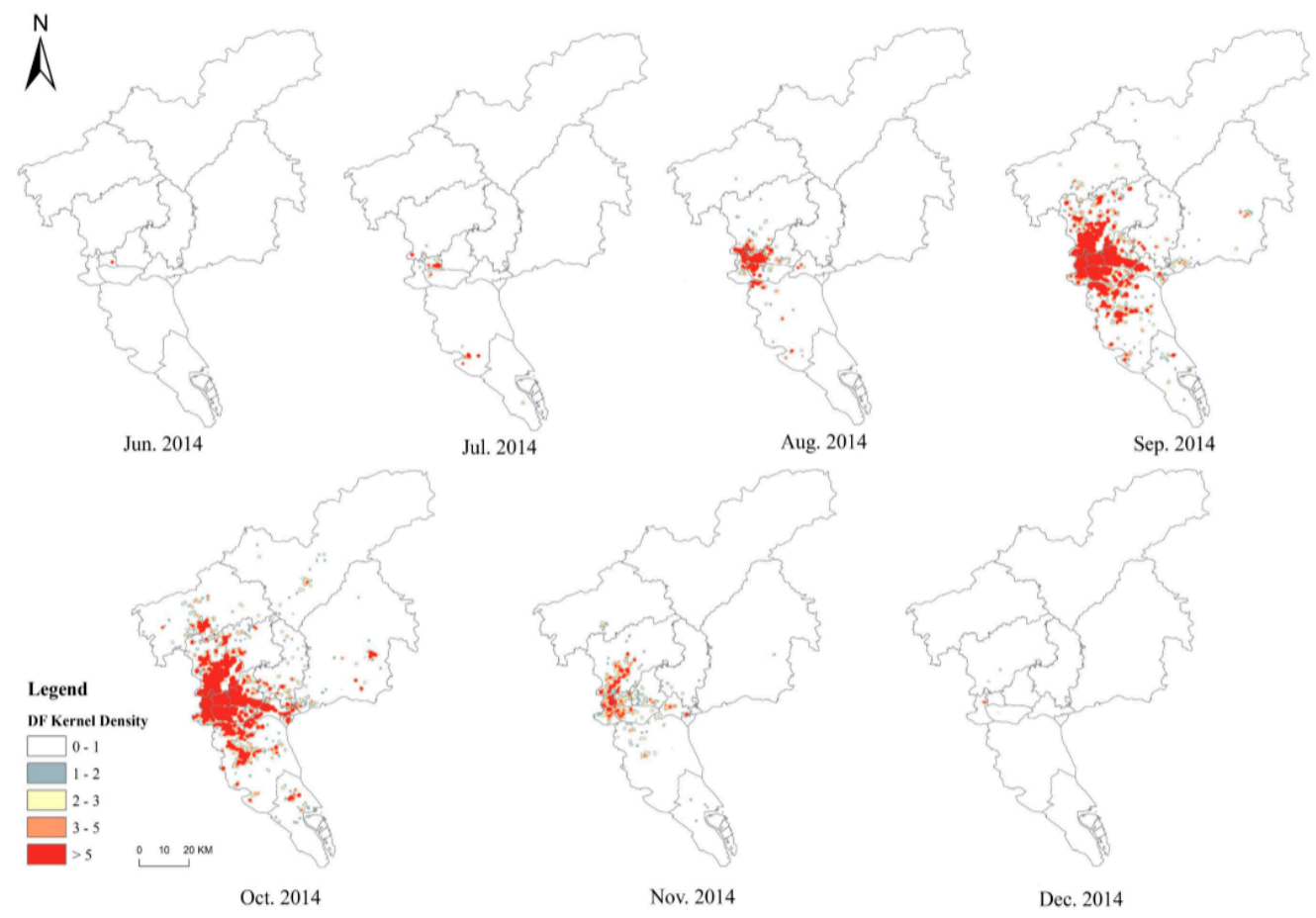

Figure 4. Transmission characteristics of DF cases. 


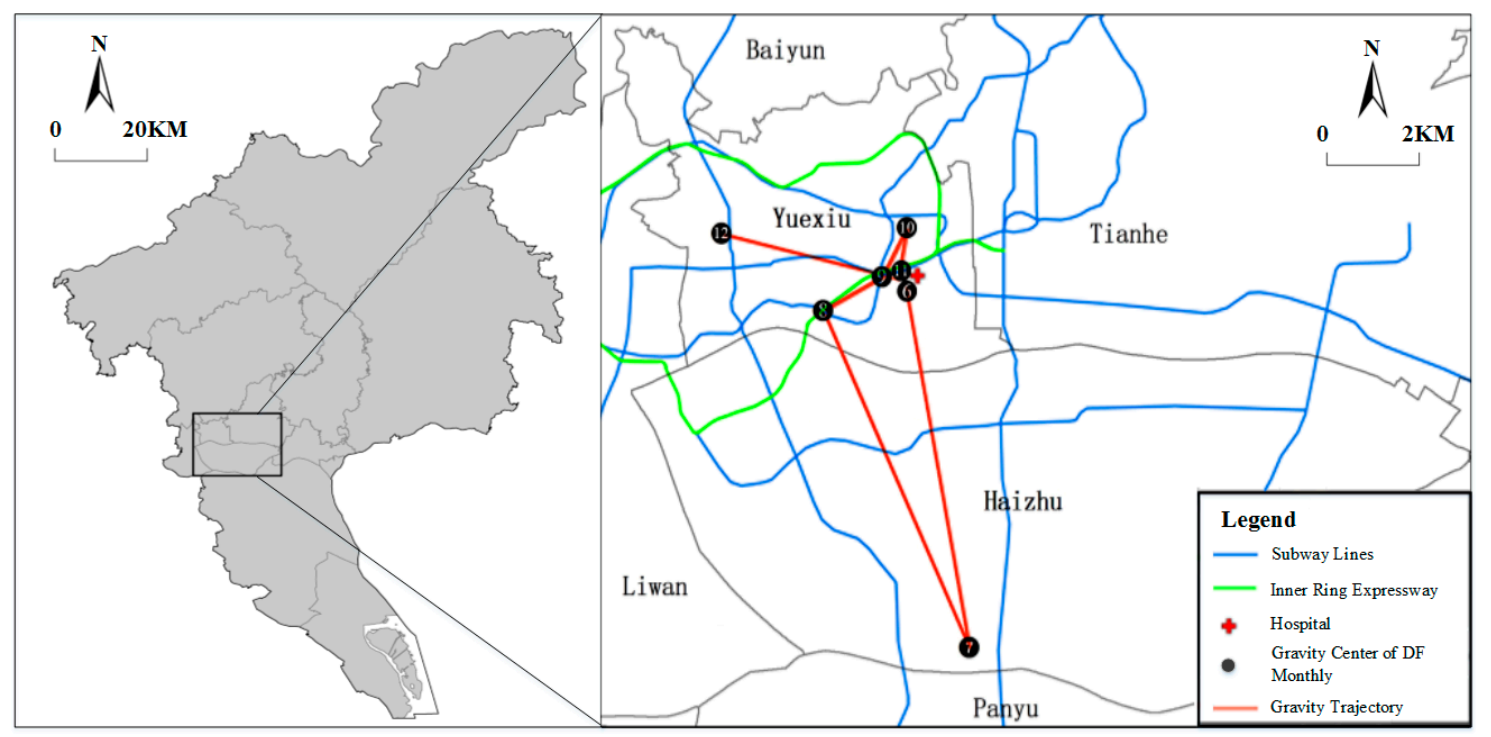

Figure 5. Distribution of the monthly gravity center of DF.

\subsection{Relationship between Dengue Fever and Driving Factors}

\subsubsection{Meteorological Factors}

Table 2 shows the cross-correlation results between DF cases and meteorological factors. It highlights that the weekly average minimum and maximum temperature had significant positive effects on the number of DF cases with a lag of 0-12 weeks. The minimum temperature with a 9-week lag had the strongest impact on DF transmission with a correlation coefficient of 0.945 and the maximum temperature with a 7-week lag had the strongest impact with a correlation coefficient of 0.917. The weekly average atmospheric pressure had a significant inverse effect on the number of DF cases with a lag of 0 to 12 weeks, and the effect of atmospheric pressure on the DF transmission was strongest at the lag of 11 weeks with a correlation coefficient of -0.92 . The weekly average relative humidity had a positive effect on the DF transmission with a lag of 8-12 weeks. 
Table 2. Cross-correlation coefficients between weekly DF cases and meteorological variables.

\begin{tabular}{ccccccccccccccc}
\hline Lag Weeks & $\mathbf{0}$ & $\mathbf{1}$ & $\mathbf{2}$ & $\mathbf{3}$ & $\mathbf{4}$ & $\mathbf{5}$ & $\mathbf{6}$ & $\mathbf{7}$ & $\mathbf{8}$ & $\mathbf{9}$ & $\mathbf{1 0}$ & $\mathbf{1 1}$ & $\mathbf{1 2}$ \\
\hline $\operatorname{Tmin}\left({ }^{\circ} \mathrm{C}\right)$ & $0.480^{* *}$ & $0.551^{* *}$ & $0.624^{* *}$ & $0.703^{* *}$ & $0.765^{* *}$ & $0.801^{* *}$ & $0.849^{* *}$ & $0.894^{* *}$ & $0.913^{* *}$ & $0.927^{* *}$ & $0.945^{* *}$ & $0.935^{* *}$ & $0.890^{* *}$ \\
$\operatorname{Tmax}\left({ }^{\circ} \mathrm{C}\right)$ & $0.588^{* *}$ & $0.642^{* *}$ & $0.712^{* *}$ & $0.783^{* *}$ & $0.833^{* *}$ & $0.850^{* *}$ & $0.878^{* *}$ & $0.917^{* *}$ & $0.901^{* *}$ & $0.882^{* *}$ & $0.862^{* *}$ & $0.840^{* *}$ & $0.786^{* *}$ \\
AP (hpa) & $-0.360^{* *}$ & $-0.414^{* *}$ & $-0.488^{* *}$ & $-0.593^{* *}$ & $-0.649^{* *}$ & $-0.705^{* *}$ & $-0.787^{* *}$ & $-0.836^{* *}$ & $-0.859^{* *}$ & $-0.895^{* *}$ & $-0.916^{* *}$ & $-0.920^{* *}$ & $-0.890^{* *}$ \\
Hum (\%) & -0.203 & $-0.155^{*}$ & -0.07 & 0.017 & 0.049 & 0.139 & $0.239^{*}$ & 0.273 & $0.329^{*}$ & $0.42^{* *}$ & $0.495^{* *}$ & $0.493^{* *}$ & $0.523^{* *}$ \\
\hline
\end{tabular}

Note: ${ }^{* *}$ Correlation is significant at the 0.01 level (2-tailed); ${ }^{*}$ Correlation is significant at the 0.05 level (2-tailed) 


\subsubsection{Human and land-Use Factors}

Table 3 shows the geo-detector results. We find that 5 factors, including population, community age, subway, road and pond, have significant impacts on the DF distribution. The population (0.624), community age (0.382) and subway (0.134) have an important impact on the DF distribution, followed by roads (0.05) and ponds (0.001).

As shown in Table 4, the interaction among land-use and human factors strengthens DF transmission, while ponds, the subway and roads were the important interaction factors. Ponds $\cap$ roads $=0.058(\uparrow 9.4 \%)(\cap$ means the interaction-effect between factors; $\uparrow$ means the increased ratio of factor interaction-effects to the simple increase of factors); ponds $\cap$ subway $=0.146(\uparrow 6.6 \%)$; and ponds $\cap$ community $=0.388(\uparrow 0.78 \%)$.

Table 3. Result of factor-detector analysis.

\begin{tabular}{cccccc}
\hline Factor & Population & Community Age & Subway & Road & Ponds \\
\hline $\mathrm{q}$ & 0.624 & 0.382 & 0.134 & 0.050 & 0.001 \\
$\mathrm{p}$ & 0.01 & 0.01 & 0.01 & 0.01 & 0.04 \\
\hline
\end{tabular}

Table 4. Result of interaction detector.

\begin{tabular}{cccccc}
\hline Factor & Population & Community Age & Subway & Road & Ponds \\
\hline Population & 0.624 & & & & \\
Community Age & 0.658 & 0.382 & & & \\
Subway & 0.643 & 0.421 & 0.134 & & \\
Road & 0.640 & 0.413 & 0.183 & 0.050 & \\
Ponds & 0.625 & 0.388 & 0.146 & 0.058 & 0.003 \\
\hline
\end{tabular}

\section{Discussion}

The analysis of the spatiotemporal transmission characteristics of DF indicated that June to October was the main period of DF transmission, and the DF hotspots were mainly concentrated in the southeast of Yuexiu district. In 2014, April to June was the rainy season in Guangzhou and the accumulated rain days reached 54 days during the period. Due to the aging infrastructure and poor drainage system, a large amount of water accumulated in Guangzhou. In addition, the average temperature of Guangzhou from April to June remained between $22^{\circ} \mathrm{C}$ and $28^{\circ} \mathrm{C}$, which was conducive to the breeding of mosquito vectors and provided good conditions for DF outbreak (June to October). A further investigation of the DF hotspots of Guangzhou revealed the following characteristics. First, the hotspots had a convenient transportation network, which was close to the subway lines and the Guangzhou inner ring expressway in space, and there were several large hospitals around it, such as the First Affiliated Hospital of Guangdong Pharmaceutical College (Figure 5), which made residents living in the aggregation area more vulnerable to DF. Second, the buildings and infrastructure in the hotspot had gradually aged due to their long service life, which provided a good environment for mosquito breeding. In the aggregation area, most of the houses were old-fashioned buildings that had been built more than 30 years ago. The aggregation area had a high-building density, and the houses were occluded from each other and surrounded by a large number of trees and shrubs, thereby increasing the number of dark and humid places. Third, there were a large number of frail elderly and immigrant people from countries with high DF incidence, which increased the risk of DF transmission.

The findings of the cross-correlation analysis showed that minimum temperature, maximum temperature, atmospheric pressure and relative humidity had a lagging effect on the DF transmission. The minimum temperature and maximum temperature had a positive lag correlation with DF transmission for $0-12$ weeks, with the strongest correlation at 9 weeks and 7 weeks, respectively. Atmospheric pressure had a negative correlation with the DF transmission, and the maximum 
correlation value was at 11 weeks. Relative humidity had a positive correlation with the DF transmission for 8-12 weeks. This was because DF is an acute mosquito-borne disease transmitted in a "human-mosquito-human" mode [5], and there was a time-lag effect from the increase of mosquito population to the increase of DF cases. Therefore, the influence of temperature, atmospheric pressure and relative humidity on the DF transmission showed a corresponding time-lag relationship. DF is an acute mosquito-borne disease transmitted by Aedes mosquitoes, and the breeding of Aedes mosquitoes required appropriate temperature, relative humidity and atmospheric pressure conditions. In general, increased ambient temperature and relative humidity accelerated the reproduction of mosquito vectors and promoted the spread of DF [1,23]. The numbers of Aedes larvae were higher in the rainy season than in the winter seasons, which made it easy to develop DF in areas with high relative humidity. The same findings were indicated by Wongkoon [29]. Morin [2] and Xiang [30] stated that a maximum temperature ranging from 21.6 to 32.9 and a minimum temperature from 11.2 to 23.7 are optimal for DF transmission, which was coincident with the annual temperature range in Guangzhou. Atmospheric pressure had an adverse effect on the DF transmission because the lower atmospheric pressure promoted the mosquito vectors flying at lower altitudes, which increased the possibility of human exposure to mosquitoes and increased the transmission risk of DF, which was consistent with the research results of Bulto [31].

The findings of the geo-detector analysis revealed that population, community age and the subway were the important driving factors affecting the DF transmission, followed by roads and ponds. In 2014, the DF hotspots in Guangzhou were mainly distributed in the places with dense population, old infrastructure and developed transportation networks. The interaction among people, DF carriers and mosquito vectors in these areas was greatly enhanced and increased the DF transmission probability. In addition, with regard to older communities, the poor sanitation conditions, a high proportion of susceptible populations (e.g., the elderly) and residents who neglected the issues of DF prevention and control strengthened the risk of DF transmission. This result was in accordance with the findings indicated by Morin and Bakhsh [2,32]. The proportion of the elderly population living in the old community was relatively larger, which increases the susceptible population and strengthens the risk of DF transmission [29]. The subway and its catchment areas were crowded places, which increased the chances of human contact with DF carriers, greatly enhancing the risk of human infection with DF (similar findings were found by Sanna and Hsieh [16]). Li [8] referred to the spread of the epidemic being mainly along the high-density road network area, and a high-density road network is an important factor contributing to the direction and scale of DF epidemics. Houses located along roads produced conducive conditions for Aedes albopictus breeding sites, resting sites, blood feeding sites, oviposition sites and areas to disperse. Additionally, compared with rivers and other flowing water, ponds had the characteristics of low-fluidity or non-fluidity and were prone to water accumulation. In the absence of natural enemies of mosquito larvae such as fish, ponds were suitable for mosquito breeding.

It is worth noting that the impact of these factors was exerted on DF risk through multiple mechanisms, and the spatial interaction of human (e.g., population, community age) and land-use factors (e.g., subway, road and ponds) could enhance the spatiotemporal transmission of DF. Furthermore, ponds were an important interaction factor because they could strengthen the influence of other factors on DF transmission. Located in the subtropical coast, the rainy season in Guangzhou is hot, humid and rainy $[10,17]$. Due to the aging of the drainage system and other infrastructure, Guangzhou often encounters urban waterlogging after heavy rains, and a large amount of accumulated standing water often appear in and around ponds, which provides the necessary water environment for the breeding of Aedes mosquitos. When the areas with high population density and high susceptibility interact spatially with water-prone areas, it could increase the exposure of humans to Aedes mosquitoes and increase the risk of DF transmission. This might be the reason that the spatial superposition of driving factors will enhance the "human-mosquito-human" [5] transmission mode of DF and accelerate the transmission speed. 
Of course, this study was not without limitations. First, we used the reported confirmed cases of DF to analyze the relationship between the spatiotemporal transmission patterns of DF and driving factors, which have implications for pre-emptive DF control. However, it should be noted that some DF cases (such as undetected DF cases) might not be included in ISND, particularly in areas with underdeveloped medical conditions [1,33]. Second, DF transmission may be affected by the age structure of urban residents [22]. However, due to the poor availability of data, we only replaced the population age structure factor with that of the community age. Considering these limitations were mainly caused by data availability, further work can focus on data collection and enrich the driving factors in this study. Moreover, landscape characteristics (e.g., compositional and configurational features) can affect the transmission of mosquito-borne diseases by affecting human density and movement, mosquito abundance and distribution and human-mosquito encounters, and landscape characterization via landscape metrics has been applied in the studies of mosquito-borne diseases, such as malaria in the Amazon [34]. This method might be used in dengue research for a deep understanding of the impact of urban landscape feature on dengue's spatiotemporal transmission. Such information might be useful for improving the actual prevention strategies of dengue transmission.

\section{Conclusions}

This study has two major strengths. Firstly, we quantified the effects of meteorological, human and land-use factors on DF transmission and built a hierarchical factor system of DF. Meteorological factors including minimum temperature, maximum temperature and humidity have a positive effect on DF transmission, while atmospheric pressure has a negative effect. Furthermore, minimum temperature, maximum temperature, atmospheric pressure and humidity have a lag effect on DF transmission. The population, community age and subway were the most important driving factors affecting DF transmission, followed by roads and ponds. Secondly, we identified that the interaction among land-use and human factors could enhance DF transmission, and the pond factor was the most important interaction factor, which could strengthen the influence of other factors on DF transmission.

Author Contributions: Y.C. conceived the study and edited the manuscript; W.L. carried out data collection; R.G., Z.L. and Z.Z. reviewed and improved the manuscript; Z.L. and Z.Y. did the statistical analyses.

Funding: This research was supported by the National Natural Science Foundation of China (NFSC) (Grant number 41801336).

Acknowledgments: The authors are grateful to the Guangdong Provincial Center for Disease Control and Prevention for facilitating the activities. The authors are grateful to Zhang Ying from Shenzhen University and Prof. Yan Bojie from Minjiang University for valuable suggestions.

Conflicts of Interest: The authors declare no conflicts of interest.

\section{References}

1. Bhatt, S.; Gething, P.W.; Brady, O.J.; Messina, J.P.; Farlow, A.W.; Moyes, C.L.; Drake, J.M.; Brownstein, J.S.; Hoen, A.G.; Sankoh, O.; et al. The global distribution and burden of dengue. Nature 2013, 496, $504-507$. [CrossRef] [PubMed]

2. Morin, C.W.; Comrie, A.C.; Ernst, K. Climate and dengue transmission: Evidence and implications. Environ. Health Perspect. 2013, 121, 1264-1272. [CrossRef] [PubMed]

3. Brady, O.J.; Gething, P.W.; Bhatt, S.; Messina, J.P.; Brownstein, J.S.; Hoen, A.G.; Moyes, C.L.; Farlow, A.W.; Scott, T.W.; Hay, S.I. Refining the global spatial limits of dengue virus transmission by evidence-based consensus. PLoS Negl. Trop. Dis. 2012, 6, e1760. [CrossRef] [PubMed]

4. Moreno-Madriñán, M.; Crosson, W.; Eisen, L.; Estes, S.; Estes, M., Jr.; Hayden, M.; Hemmings, S.; Irwin, D.; Lozano-Fuentes, S.; Monaghan, A.; et al. Correlating remote sensing data with the abundance of pupae of the dengue virus mosquito vector, Aedes aegypti, in Central Mexico. ISPRS Int. J. Geo-inf. 2014, 3, 732-749. [CrossRef]

5. Ribeiro, C.F.; Lopes, V.G.S.; Brasil, P.; Pires, A.R.C.; Rohloff, R.; Nogueira, R.M.R. Dengue infection in pregnancy and its impact on the placenta. Int. J. Infect. Dis. 2017, 55, 109-112. [CrossRef] [PubMed] 
6. Wen, T.H.; Lin, M.H.; Teng, H.J.; Chang, N.T. Incorporating the human- Aedes mosquito interactions into measuring the spatial risk of urban dengue fever. Appl. Geogr. 2015, 62, 256-266. [CrossRef]

7. Lee, H.S.; Nguyen-Viet, H.; Nam, V.S.; Lee, M.; Won, S.; Duc, P.P.; Grace, D. Seasonal patterns of dengue fever and associated climate factors in 4 provinces in Vietnam from 1994 to 2013. BMC Infect. Dis. 2017, 17, 218. [CrossRef] [PubMed]

8. Li, Q.; Cao, W.; Ren, H.; Ji, Z.; Jiang, H. Spatiotemporal responses of dengue fever transmission to the road network in an urban area. Acta Trop. 2018, 183, 8-13. [CrossRef] [PubMed]

9. Guzman, M.G.; Harris, E. Dengue. Lancet 2015, 385, 453-465. [CrossRef]

10. Liu, K.; Sun, J.; Liu, X.; Li, R.; Wang, Y.; Lu, L.; Wu, H.; Gao, Y.; Xu, L.; Liu, Q. Spatiotemporal patterns and determinants of dengue at county level in China from 2005-2017. Int. J. Infect. Dis. 2018, 77, 96-104. [CrossRef]

11. Scott, T.W.; Morrison, A.C. Vector dynamics and transmission of dengue virus: Implications for dengue surveillance and prevention strategies. Curr. Top. Microbiol. Immunol. 2010, 338, 115-128. [PubMed]

12. Mahmood, S.; Irshad, A.; Nasir, J.M.; Sharif, F.; Farooqi, S.H. Spatiotemporal analysis of dengue outbreaks in Samanabad town, Lahore metropolitan area, using geospatial techniques. Environ. Monit. Assess. 2019, 191, 55. [CrossRef] [PubMed]

13. Åström, C.; Rocklöv, J.; Hales, S.; Béguin, A.; Louis, V.; Sauerborn, R. Potential distribution of dengue fever under scenarios of climate change and economic development. Ecohealth 2012, 9, 448-454. [CrossRef] [PubMed]

14. Savargaonkar, D.; Sinha, S.; Srivastava, B.; Nagpal, B.N.; Sinha, A.; Shamim, A.; Das, R.; Pande, V.; Anvikar, A.R.; Valecha, N. An epidemiological study of dengue and its coinfections in Delhi. Int. J. Infect. Dis. 2018, 74, 41-46. [CrossRef] [PubMed]

15. Hagenlocher, M.; Delmelle, E.; Casas, I.; Kienberger, S. Assessing socioeconomic vulnerability to dengue fever in Cali, Colombia: Statistical vs expert-based modeling. Int. J. Health Geogr. 2013, 12, 36. [CrossRef] [PubMed]

16. Sanna, M.; Hsieh, Y.-H. Ascertaining the impact of public rapid transit system on spread of dengue in urban settings. Sci. Total Environ. 2017, 598, 1151-1159. [CrossRef] [PubMed]

17. Ren, H.; Zheng, L.; Li, Q.; Yuan, W.; Lu, L. Exploring determinants of spatial variations in the Dengue Fever epidemic using geographically weighted regression model: A case study in the joint Guangzhou-Foshan Area, China, 2014. Int. J. Environ. Res. Public Health 2017, 14, 1518. [CrossRef] [PubMed]

18. Balmaseda, A.; Hammond, S.N.; Perez, L.; Tellez, Y.; Saborio, S.I.; Mercado, J.C.; Cuadra, R.; Rocha, J.; Perez, M.A.; Silva, S.; et al. Serotype-specific differences in clinical manifestations of dengue. Am. J. Trop. Med. Hyg. 2006, 74, 449-456. [CrossRef] [PubMed]

19. Atique, S.; Chan, T.C.; Chen, C.C.; Hsu, C.Y.; Iqtidar, S.; Louis, V.R.; Shabbir, S.A.; Chuang, T.W. Investigating spatio-temporal distribution and diffusion patterns of the dengue outbreak in Swat, Pakistan. J. Infect. Public Health 2018, 11, 550-557. [CrossRef]

20. Hsueh, Y.H.; Lee, J.; Beltz, L. Spatio-temporal patterns of dengue fever cases in Kaoshiung City, Taiwan, 2003-2008. Appl. Geogr. 2012, 34, 587-594. [CrossRef]

21. Santos, C.A.G.; Guerra-Gomes, I.C.; Gois, B.M.; Peixoto, R.F.; Keesen, T.S.L.; da Silva, R.M. Correlation of dengue incidence and rainfall occurrence using wavelet transform for Joao Pessoa city. Sci. Total Environ. 2019, 647, 794-805. [CrossRef] [PubMed]

22. Kikuti, M.; Cunha, G.M.; Paploski, I.A.; Kasper, A.M.; Silva, M.M.; Tavares, A.S.; Cruz, J.S.; Queiroz, T.L.; Rodrigues, M.S.; Santana, P.M.; et al. Spatial Distribution of Dengue in a Brazilian Urban Slum Setting: Role of Socioeconomic Gradient in Disease Risk. Plos Negl. Trop. Dis. 2015, 9, e0003937. [CrossRef] [PubMed]

23. World Health Organization. Dengue Guidelines for Diagnosis, Treatment, Prevention and Control; World Health Organization: Geneva, Switzerland, 2009; pp. 14-67.

24. Xu, H.Y.; Fu, X.; Lee, L.K.H.; Ma, S.; Goh, K.T.; Wong, J.; Habibullah, M.S.; Lee, G.K.K.; Lim, T.K.; Tambyah, P.A.; et al. Statistical Modeling Reveals the Effect of Absolute Humidity on Dengue in Singapore. Plos Negl. Trop. Dis. 2014, 8, e2805. [CrossRef] [PubMed]

25. Rosa-Freitas, M.G.; Schreiber, K.V.; Tsouris, P.; Weimann, E.T.D.S.; Luitgards-Moura, J.F. Associations between dengue and combinations of weather factors in a city in the Brazilian Amazon. Revista Panamericana Salud Pública 2006, 20, 256-267. [CrossRef] [PubMed] 
26. Chen, Z.; Chen, D.; Xie, X.; Cai, J.; Zhuang, Y.; Cheng, N.; He, B.; Gao, B. Spatial self-aggregation effects and national division of city-level PM2.5 concentrations in China based on spatio-temporal clustering. J. Clean. Prod. 2019, 207, 875-881.

27. Luo, L.; Mei, K.; Qu, L.; Zhang, C.; Chen, H.; Wang, S.; Di, D.; Huang, H.; Wang, Z.; Xia, F.; et al. Assessment of the Geographical Detector Method for investigating heavy metal source apportionment in an urban watershed of Eastern China. Sci. Total Environ. 2019, 653, 714-722. [CrossRef] [PubMed]

28. Wang, J.; Zhang, T.; Fu, B. A measure of spatial stratified heterogeneity. Ecol. Indic. 2016, 67, $250-256$. [CrossRef]

29. Wongkoon, S.; Jaroensutasinee, M.; Jaroensutasinee, K. Weather factors influencing the occurrence of dengue fever in Nakhon Si Thammarat, Thailand. Trop. Biomed. 2013, 30, 631-641. [PubMed]

30. Xiang, J.; Hansen, A.; Liu, Q.; Liu, X.; Tong, M.X.; Sun, Y.; Cameron, S.; Hanson-Easey, S.; Han, G.S.; Williams, C.; et al. Association between dengue fever incidence and meteorological factors in Guangzhou, China, 2005-2014. Environ. Res. 2017, 153, 17-26. [CrossRef] [PubMed]

31. Bultó, P.L.O.; Rodríguez, A.P.; Valencia, A.R.; Vega, N.L.; Gonzalez, M.D.; Carrera, A.P. Assessment of Human Health Vulnerability to Climate Variability and Change in Cuba. Environ. Health Perspect. 2007, 114, 1942-1949. [CrossRef] [PubMed]

32. Bakhsh, K.; Sana, F.; Ahmad, N. Dengue fever in Punjab, Pakistan: Knowledge, perception and adaptation among urban adults. Sci. Total Environ. 2018, 644, 1304-1311. [CrossRef] [PubMed]

33. Silva, M.M.; Rodrigues, M.S.; Paploski, I.A.; Kikuti, M.; Kasper, A.M.; Cruz, J.S.; Queiroz, T.L.; Tavares, A.S.; Santana, P.M.; Araujo, J.M.; et al. Accuracy of dengue reporting by national surveillance system, Brazil. Emerg. Infect. Dis. 2016, 22, 336-339. [CrossRef] [PubMed]

34. Li, Z.; Roux, E.; Dessay, N.; Girod, R.; Stefani, A.; Nacher, M.; Moiret, A.; Seyler, F. Mapping a knowledge-based malaria hazard index related to landscape using remote sensing: Application to the cross-border area between French Guiana and Brazil. Remote Sens. 2016, 8, 319. [CrossRef] 